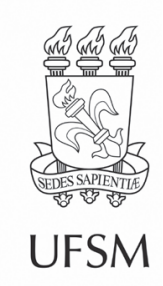

\title{
Artigos
}

\section{Decomposição foliar visando ao monitoramento de áreas em processo de restauração ecológica no Mato Grosso do Sul}

\author{
Leaf litter decomposition aiming the monitoring of areas in ecological \\ restoration process in Mato Grosso do Sul state
}

\author{
Caroline Quinhones Fróes ${ }^{\oplus}{ }^{\oplus}$, Shaline Séfara Lopes Fernandes" ${ }^{\oplus}$, \\ Mário Soares Junglos ${ }^{\prime \prime \prime} \oplus$, Poliana Ferreira da Costaiv $\odot$, \\ Jósimo Diego Bazanella Linê ${ }^{\prime \prime \prime} \oplus$, Zefa Valdivina Pereira"II $\odot$ \\ 'Prefeitura Municipal de Ponta Porã, Ponta Porã, MS, Brasil \\ "Universidade Estadual de Mato Grosso do Sul, Cassilândia, MS, Brasil \\ "'Universidade Federal da Grande Dourados, Dourados, MS, Brasil \\ vUniversidade Estadual do Mato Grosso do Sul, Coxim, MS, Brasil
}

\section{RESUMO}

O processo de decomposição auxilia no equilíbrio e funcionamento dos ecossistemas florestais por meio da liberação de nutrientes para o sustento das plantas. O objetivo foi avaliar a decomposição foliar como indicador de funcionalidade em três áreas restauradas por plantio de mudas com mais de dez anos, no Mato Grosso do Sul. O estudo foi realizado em 2017, nos municípios de Ivinhema, 13 anos após o plantio (IV-13); Jateí, com 14 anos de plantio (JA-14); e Caarapó, com 17 anos de plantio (CA-17). Folhas recém-caídas foram coletadas, secas em estufa a $65^{\circ} \mathrm{C}$, pesadas em porções de 10 gramas e colocadas em sacos de decomposição (litterbags), distribuídos aleatoriamente sobre o piso florestal das áreas. Para avaliar a perda da biomassa seca, foram retirados 10 litterbags aos 30, 60, 90, 120, 150 e 180 dias após instalação. Foram estimados o percentual de massa remanescente, a taxa de decomposição ( $k$ ), o tempo de meia-vida ( $t$ 1 12 ) e a correlação de Pearson ( $r$ ) entre a massa remanescente e a precipitação e temperatura. A ( $k$ ) no período de 180 dias para CA-17 foi de 0,004 g g- ${ }^{-1}$ dia- $^{-1}$ e 0,003 g g-1 dia-1 para IV-13 e JA-14, já o (t 1/2) foi de 269,49 dias para IV-13, 218,29 para JA-14 e 194,89 dias para CA-17. A ( $r$ ) foi fraca para todas as áreas e variáveis, exceto IV-13 que obteve ( $r$ ) moderada para a precipitação. A idade dos plantios não é determinante, a decomposição é regida principalmente pelas características internas e externas das áreas. O indicador foi eficiente na compreensão das taxas de decomposição, constatando perda de massa foliar mais acelerada para CA-17 e JA-14, o que pode resultar na mais rápida liberação de nutrientes para o solo e retorno à vegetação. Recomenda-se a utilização de indicadores complementares para compreensão holística da dinâmica de ecossistemas em restauração.

Palavras-chave: Litterbags; Resíduos vegetais; Perda de massa; Indicador de funcionalidade 


\section{ABSTRACT}

The decomposition process helps in the balance and functioning of forest ecosystems by providing essential nutrients for the sustenance of plants. The objective was to evaluate the leaf decomposition as an indicator of functionality in three areas of environmental restoration by the planting of seedlings over ten years old in Mato Grosso do Sul state. The study was conducted in 2017 in the municipalities of Ivinhema, 13 years after planting (IV-13), Jateí at the age of 14 (JA-14) and Caarapó, 17 years old after planting (CA-17). Leaves of the forest floor surface were collected, oven dried at $65^{\circ} \mathrm{C}$ and weighed in 10-gram portions to be placed in the litterbags, randomly distributed on the forest floor surface. To evaluate the loss of dry biomass, 10 litterbags were removed at 30,60, 90, 120, 150 and 180 days after installation. The percentage of the remaining mass, decomposition rates $(k)$, the half-life ( $1 / 2)$ and Pearson's correlation ( $r$ ) between the remaining mass and precipitation and temperature were estimated. The $(k)$ in the 180-day period for CA-17 was $0.004 \mathrm{~g} \mathrm{~g}^{-1}$ day ${ }^{-1}$ and $0.003 \mathrm{~g} \mathrm{~g}^{-1}$ day ${ }^{-1}$ for IV-13 and JA-14, to the ( $\mathrm{t}$ 1/2) was 269,49 days for IV-13, 218,29 for JA-14 and 194,89 days for CA-17. The ( $r$ ) was weak for all areas and variables, except IV-13, which obtained moderate $(r)$ for precipitation. The age of the plantations is not decisive, the decomposition is mainly governed by the internal and external characteristics of the areas. The indicator was efficient in understanding the decomposition rates, confirming a more accelerated foliar mass for CA-17 and JA-14, which can result in the faster release of nutrients to the soiland return to vegetation. It is recommended to use complementary indicators for a holistic understanding of the dynamics of ecosystems in restoration.

Keywords: Litterbags; Vegetable residues; Mass loss; Functionality indicator

\section{INTRODUÇÃO}

A serapilheira é o material encontrado na superfície do solo, composta em sua maioria por resíduos vegetais, como folhas, cascas, ramos, flores, frutos, sementes e, em menor proporção, detritos de origem animal. Trata-se de um importante processo ecológico no funcionamento do ecossistema florestal, atuando como um sistema de entrada e saída de nutrientes por meio da produção e decomposição (MARTINS; RODRIGUES, 1999; CUNHA-NETO et al., 2013).

Como cerca de 50 a $80 \%$ da serapilheira é representada por material foliar (PAULA; PEREIRA; MENEZES, 2009; PIMENTA et al., 2011), estudos têm utilizado essa fração vegetal para compreender a dinâmica da decomposição de ecossistemas florestais em processo de restauração (NUNES; PINTO, 2012; MIRANDA NETO et al., 2015), visto que ela é responsável pela maior parte e mais rápida liberação de nutrientes via decomposição (VIERA et al., 2014). 
A decomposição permite que parte do carbono incorporado na biomassa vegetal volte à atmosfera como $\mathrm{CO}_{2}$ e outra parte, juntamente com os elementos minerais, seja integrada ao solo (OLSON, 1963). É determinante para o equilíbrio, funcionamento e manutenção dos ecossistemas florestais (PINTO et al., 2016), uma vez que ela influencia na formação de matéria orgânica do solo e disponibilidade de nutrientes para as plantas (CALDEIRA et al., 2013), regulando a produtividade da floresta.

A velocidade do processo de decomposição em ecossistemas terrestres é determinada por fatores bióticos e abióticos, podendo ser regida pela precipitação, temperatura, qualidade do substrato, diversidade e abundância de organismos da fauna do solo (BARGALI et al., 2015). Os tipos de florestas, a densidade da vegetação, o estágio sucessional, a composição de espécies e a época de coleta também podem influenciá-la (CALDEIRA et al., 2013). Para Wang et al. (2015), os fatores ambientais podem trazer consequências diretas, interferindo na quantidade e na qualidade da decomposição orgânica em questão, e indiretas, influenciando as condições ambientais e regulando as atividades dos organismos decompositores.

Alterações nas taxas de decomposição refletem no funcionamento do ecossistema e produtividade, principalmente quando se trata de florestas tropicais, que geralmente têm sua vegetação sustentada por solos com baixa fertilidade e que se enriquecem por meio do suprimento dos nutrientes advindos, em sua maioria, do processo de decomposição da serapilheira (GIEBELMANNA et al., 2010; WANG et al., 2015).

Em vista de sua importância na regulação do acúmulo de serapilheira e ciclagem de nutrientes (PINTO et al., 2016) e de sua sensibilidade e resposta às condições ambientais, a decomposição da serapilheira é considerada um indicador de reação (SCORIZA; PIÑA-RODRIGUES, 2013) e, portanto, tem sido estudada como indicador em florestas naturais e em restauração ambiental para fins de monitoramento (MIRANDA NETO et al., 2015; BAUER; FÜHR; SCHMITT, 2017). 
Considerando a escassez de estudos de decomposição em áreas de restauração ecológica no estado do Mato Grosso do Sul, três áreas restauradas por plantio de mudas com mais de dez anos foram foco deste estudo. O plantio no município de Ivinhema com 13 anos pós-implantação, denominado (IV-13) abrange uma área de 4,68 hectares com a utilização de 37 espécies na restauração. Conforme levantamento florístico de Costa et al. (2017) realizado em 1 hectare, essa área caracteriza-se com 1.651 indivíduos arbóreos, 19 famílias e 46 espécies, sendo a maioria Pioneiras (39\%) e Zoocóricas (48\%) com algumas das espécies mais abundantes representadas por Guazuma ulmifolia Lam., Mabea fistulifera Mart., Inga vera Willd., Senegalia polyphylla (DC.) Britton, Inga laurina (Sw.) Willd., Croton urucurana Baill. e Anadenanthera colubrina (Vell.) Brenan. IV-13 apresenta dossel relativamente aberto, com inúmeras clareiras que propiciam a proliferação massiva de gramínea invasora e trata-se de um fragmento isolado sem conectividade com áreas florestais remanescentes, apenas áreas agrícolas no entorno.

O plantio referente à Jateí de 14 anos (JA-14) possui área de 4,71 hectares, no qual, no ato da implantação foram utilizadas 125 espécies arbóreas. Costa et al. (2017) identificaram em 1 hectare, 1.988 indivíduos, 41 famílias e 106 espécies, sendo a maioria Pioneiras (42\%) e Zoocóricas (52\%), com algumas das mais abundantes representadas por Croton floribundus Spreng., Handroanthus heptaphyllus (Vell.) Mattos, Anadenanthera colubrina (Vell.) Brenan., Dipteryx alata Vogel, Citharexylum myrianthum Cham.e Maclura tinctoria (L.) D.Don ex Steud. Possui dossel mais fechado, com presença de algumas clareiras, pouca predominância de gramínea invasora e é privilegiada por estar conectada a uma Área de Preservação Permanente de 7,9 hectares e fragmento próximo a 50 metros com 13 hectares.

Quanto ao plantio de 17 anos localizado em Caarapó (CA-17), não há informação sobre o número de espécies utilizadas na implantação. Entretanto, em estudo recente, 1 hectare é representado por 1.990 indivíduos, 36 famílias e 77 espécies, predominantemente Secundárias Tardias (36\%) e Zoocóricas (68\%), sendo as mais 
ocorrentes Machaerium acutifolium Vogel, Moquiniastrum polymorphum (Less.) G. Sancho, Ilexparaguariensis A.St.-Hil., Peltophorum dubium (Spreng.) Taub., Chrysophyllum marginatum (Hook. \& Arn.) Radlk. e Handroanthus impetiginosus (Mart. ex DC.) Mattos conforme Costa et al. (2017). Seu dossel é muito fechado, o solo é quase ausente de gramínea invasora e bastante expressivo em regeneração natural arbustivo-arbórea, além de possuir conexão a fragmento florestal de 8,9 hectares.

Em áreas de restauração florestal, o estudo da dinâmica da serapilheira pode ser considerado um indicador de funcionalidade do ecossistema, auxiliando no monitoramento ambiental e na verificação do êxito das técnicas implantadas. Nesse sentido, o objetivo da pesquisa foi avaliar a decomposição da serapilheira foliar de três áreas de restauração ecológica do Mato Grosso do Sul com mais de dez anos após plantio de mudas, visando a sua aplicação como potencial indicador de monitoramento ambiental.

\section{MATERIAL E MÉTODO}

\section{1 Áreas de estudo}

A avaliação da decomposição foliar foi realizada de março a setembro de 2017 em três áreas de restauração por plantio de mudas arbóreas nativas no estado do Mato Grosso do Sul, sob espaçamento $3 \times 2 \mathrm{~m}^{2}$, localizadas nos municípios de Caarapó (Lat. 5458'03.89" O e Lon. 22³5'28.40" S com elevação de 495 metros), Jateí (Lat. 54¹9'30.24" O e Lon. 22³1'32.44" S e 348 metros de elevação) e Ivinhema (Lat. 5355'09.58" O e Lon. 22²2'10.69" S e 425 metros de elevação). As áreas foram implantadas nos anos 2000, 2003 e 2004, respectivamente.

Quanto ao solo, na área de restauração de Caarapó predomina-se o Latossolo Vermelho Ácrico, de textura arenosa. Para a área de Jateí, o solo é caracterizado principalmente por Argissolo Vermelho, de textura arenosa. Em Ivinhema, predomina-se o Latossolo com baixa fertilidade natural, tanto de textura argilosa 
quanto média, além da ocorrência de Nitossolos de textura arenoargilosa (MATO GROSSO DO SUL, 2016).

A vegetação original das áreas é classificada como Floresta Estacional Semidecidual e o clima da região é do tipo Aw, com transição entre tropical e subtropical representado por inverno seco, verão chuvoso, sendo a temperatura média do mês mais frio inferior a $18^{\circ} \mathrm{C}$ e mês mais quente superior a $22^{\circ} \mathrm{C}$, registrando precipitação média anual de 1.400 a 1.700 mm (MATO GROSSO DO SUL, 2016).

\subsection{Decomposição foliar}

A serapilheira utilizada para a avaliação da decomposição foi coletada dentro das respectivas áreas de estudo, utilizando-se o material encontrado na superfície do solo. Posteriormente, as amostras foram encaminhadas ao laboratório para a separação da fração foliar. O material foi seco em estufa de circulação forçada de ar a $65^{\circ} \mathrm{C}$ por 72 horas e em seguida foi realizada a pesagem de 10 gramas conforme Anderson e Ingram (1996) para inserir em cada bolsa de litterbag. O litterbag utilizado é constituído de material de polivinil, para resistir às condições ambientais em campo e possui dimensão de $20 \times 20 \mathrm{~cm}$, com malha de $5 \mathrm{~mm}$ de espessura. Essas dimensões permitem a entrada de pequenos organismos da fauna do solo, como cupins, besouros e artrópodes, assim como micro-organismos (bactérias, fungos, nematoides e protozoários) (PINTO et al., 2016).

Para cada área foram utilizados 60 litterbags, que foram etiquetados e distribuídos aleatoriamente na superfície do piso florestal em março de 2017. Aos 30, 60, 90, 120, 150 e 180 dias foram retiradas 10 repetições por área, para avaliar a taxa de decomposição pela análise de perda de massa ao longo do tempo. O tempo de avaliação da decomposição foi definido com base nos intervalos utilizados por diversos autores, que variaram de 120 a 180 dias (MENEZES et al., 2010; FERREIRA et al., 2014; PINTO et al., 2016). 
Após a coleta, os litterbags foram encaminhados para o laboratório e com o auxílio de um pincel fino, excessos de solos aderidos na serapilheira advindos do ambiente externo, e de organismos presos às folhas foram retirados. A serapilheira foi seca em estufa de circulação de ar forçada a $65^{\circ} \mathrm{C}$ por 72 horas e pesada em balança semianalítica de precisão, sendo realizada a quantificação da massa remanescente (\%) $=($ massa final $/$ massa inicial $) \times 100$.

Após o cálculo da massa remanescente ao longo do período, a constante de composição k foi calculada, segundo modelo exponencial ajustado, de acordo com Olson (1963) e o tempo de meia-vida (t¹/2), que corresponde ao tempo necessário para que ocorra a transformação de metade da quantidade inicial do folhedo, foi calculado segundo Rezende et al. (1997).

Aplicou-se a análise de variância (ANOVA), seguida pelo teste de Tukey, a 5\% de probabilidade, para comparar o percentual da massa foliar remanescente nos diferentes períodos de coleta e também a correlação linear simples de Pearson (r) entre a massa foliar remanescente da serapilheira e as variáveis ambientais (precipitação e temperatura). Os valores de (r) podem variar de -1, 0 a 1 e são classificados qualitativamente, segundo Callegari-Jacques (2003), da seguinte forma: 0,00 a 0,30 fraca correlação; 0,30 a 0,60 moderada correlação; 0,60 a 0,90 forte correlação; 0,90 a 1 correlação muito forte.

Os dados das varáveis ambientais utilizadas compreendem o período de decomposição (março a setembro de 2017) e são advindos da estação meteorológica do município de Ivinhema (Ivinhema - TRMM.1012 / AGRITEMPO: 01/03/00 - 29/10/17), do sensor automático do município de Jateí (Jateí - TRMM.1010 / AGRITEMPO: 01/03/00 - 29/10/17), e do sensor automático do município de Caarapó (Caarapó - TRMM.1008 / AGRITEMPO: 01/03/00 - 29/10/17) disponibilizados pelo INMET (Instituto Nacional de Meteorologia), por meio do Sistema de Monitoramento Agrometereológico AGRITEMPO (AGRITEMPO, 2017). 
As maiores temperaturas médias registradas são de $26^{\circ} \mathrm{C}$ e as menores de $19^{\circ} \mathrm{C}$. A área de JA-14 apresenta maior precipitação para os meses de abril $(207,4 \mathrm{~mm})$ e agosto $(127,4 \mathrm{~mm})$ e menor em julho $(8 \mathrm{~mm})$. A maior precipitação para CA-17 é registrada em abril $(234,8 \mathrm{~mm})$ e agosto $(128,5 \mathrm{~mm})$, e a menor no mês de julho $(2,1$ mm). Para IV-13, os meses de maior intensidade de precipitação são março (253,8 $\mathrm{mm}$ ) e agosto (161,5 mm) e o de menor incidência julho (5,3 mm) (Figura 1).

Figura 1 - Registro das variáveis ambientais durante o período experimental da decomposição da serapilheira nas três áreas de restauração ecológica do Mato Grosso do Sul

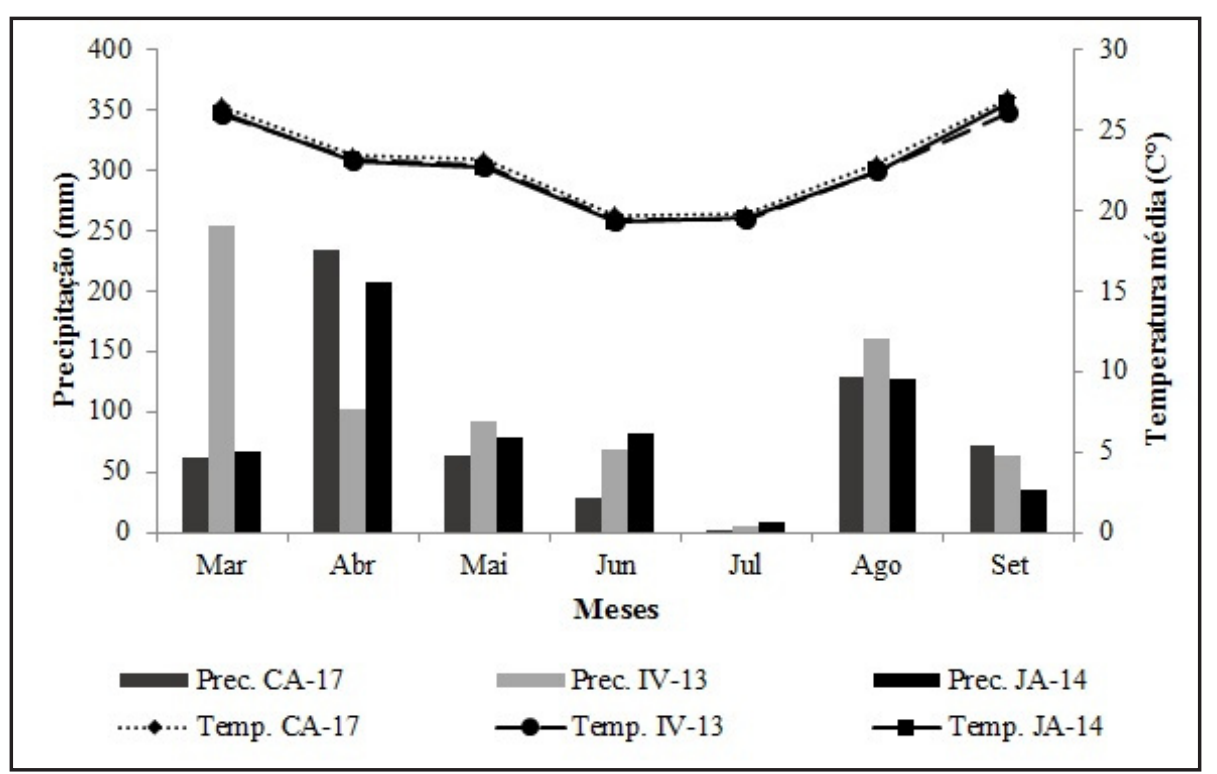

Fonte: AGRITEMPO (2017)

\section{RESULTADOS E DISCUSSÃO}

Os resultados do percentual da massa foliar remanescente apontam de modo geral uma tendência decrescente e velocidade de decomposição expressiva para a área CA-17, seguida de JA-14 e por último, IV-13 (Figura 2).

Quanto à massa foliar remanescente para CA-17, houve diferenças significativas entre as épocas avaliadas ao longo dos 180 dias, exceto entre os 60 e 120 dias, em que 
houve uma estabilidade da decomposição e os resultados mantiveram semelhanças. Destaca-se uma rápida decomposição inicial, sendo verificado que aos 30 dias houve uma queda significativa de $20 \%$ na massa remanescente, perfazendo $80 \%$. Aos 180 dias, o resultado foi de 52\%, o que significa uma perda de $48 \%$ do total inicial (Figura 2).

Figura 2 - Massa foliar remanescente da serapilheira de três áreas de restauração por plantio de mudas no estado de Mato Grosso do Sul, Brasil, durante o período de 180 dias

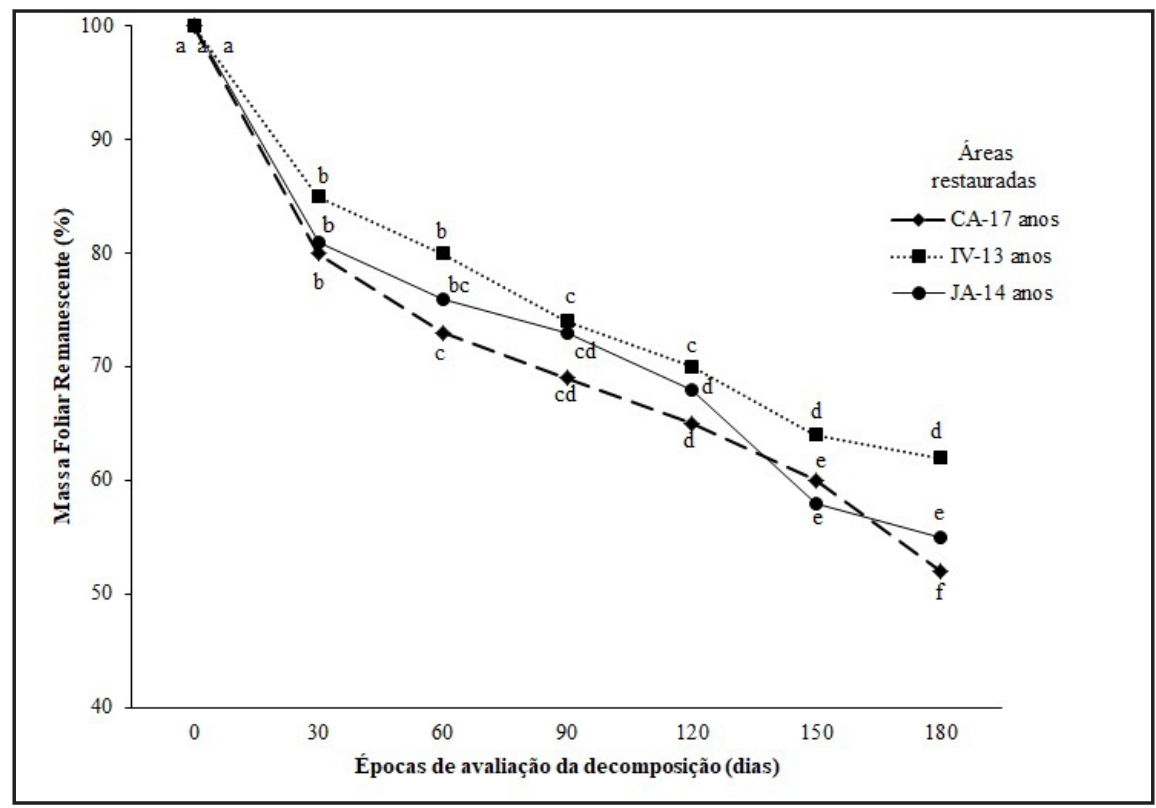

Fonte: Autores (2019)

Em que: CA-17 (Caarapó - 17 anos); IV-13 (Ivinhema - 13 anos); JA-14 (Jateí - 14 anos).

A área JA-14 também obteve queda significativa aos 30 dias, com perda de 19\% do total da massa foliar. A partir desse período, ocorreu pouca variação ao longo dos resultados, sendo que aos 60 e 90 dias houve semelhança significativa, com 76\% e $73 \%$, respectivamente. Aos 120 dias, a massa remanescente foi de $68 \%$ e aos 150 dias houve diferença significativa, com 58\%. Aos 180 dias não foi constatada significância entre o período anterior (55\%). Esse dado determinou uma perda de $45 \%$ do total referido ao início de implantação (Figura 2). 
A perda de massa foliar para IV-13 foi significativa aos 30 dias, com percentual de $85 \%$, representando queda de $15 \%$ do valor inicial. A decomposição estabilizou-se e somente aos 90 dias foi possível observar significância, com valor de 74\%. Aos 150 e 180 dias, a massa foliar atingiu os percentuais de 64 e 62\%, sendo a última avaliação representada por uma baixa de $38 \%$ do montante (Figura 2).

Para todas as áreas, a perda da biomassa foi mais acelerada inicialmente, aos 30 dias (Figura 2). Esse comportamento é comum e também foi relatado em outros estudos em florestas secundárias (MENEZES et al., 2010; FERREIRA et al., 2014) e um dos fatores que explicam tal resultado é que os nutrientes menos resistentes são lixiviados mais facilmente nessa fase e o material vegetal encontra-se mais palatável aos detritívoros (PAULA; PEREIRA; MENEZES, 2009; BIASI; CEREZER; SANTOS, 2016). Possivelmente, os picos de chuva e temperatura no período de abril também intensificaram o processo de decomposição. Conforme Holanda et al. (2015), tais variáveis auxiliam na redução dos teores de elementos químicos da serapilheira foliar e no aumento da ação dos organismos decompositores.

Nas três áreas de estudo, nos meses de junho a julho (90 a 120 dias), houve uma estabilização da decomposição da serapilheira, que pode ser justificada devido à diminuição das taxas de precipitação e temperaturas anteriormente observadas e que por sua vez atuam diretamente na redução da atividade dos organismos decompositores. Conforme Grugiki et al.(2017), a menor ocorrência de chuvas interfere na atividade biológica do solo e reduz a taxa de decomposição do material. Além disso, segundo Xu et al. (2004), após a fase inicial de lixiviação dos compostos mais solúveis que desencadeiam a decomposição mais acelerada é comum a ocorrência de um período de lentidão da perda de massa, em vista da presença de componentes químicos recalcitrantes no material vegetal, tais como a lignina e polifenóis.

Os resultados de massa foliar remanescente obtidos para as três áreas de restauração no decorrer de todas as épocas avaliadas foram similares aos encontrados por Machado et al. (2015) nos estágios inicial - 20 anos e médio - 25 anos, em fragmentos 
de Floresta Estacional Semidecidual Submontana, o que pode expressar uma resposta positiva, por se tratar de florestas plantadas de idades inferiores.

Ressalta-se que as diferenças nas taxas de decomposição entre florestas tropicais são associadas a aspectos de cada ambiente, que podem diferir frente às condições climáticas, composição vegetal, cobertura florestal, umidade do solo, característica físico-química da serapilheira, atividade dos organismos edáficos, como os fungos, bactérias, invertebrados do solo, todos atuando de maneira conjunta na decomposição da serapilheira (HÄTTENSCHWILER et al., 2011).

Observa-se que IV-13 foi a área com menor perda de massa foliar, perfazendo maior percentual ao final dos 180 dias (Figura 2). Acredita-se que esse resultado não tem relação com a idade do plantio e sim com as condições internas da área, influenciadas principalmente pela composição vegetal, característica sucessional e riqueza de espécies. A área IV-13 possui riqueza de espécies menor que as demais e é predominantemente pioneira (COSTA et al., 2017), com espécies dependentes de maior luminosidade para se desenvolverem e que possuem porte arbóreo e ciclo de vida menor, diferindo do comportamento das classes mais tardias de sucessão. Conforme observações no local, verificou-se que IV-13 possui pioneiras como Guazuma ulmifolia Lam., Croton urucurana Baill. e Cecropia pachystachya Trécul em senescência, além da mortalidade de algumas, propiciando a abertura de clareiras e a proliferação de gramínea invasora (Urochloa decumbens. (Stapf) R.D.Webster).

A composição vegetal, a riqueza, a característica peculiar de cada espécie como o crescimento e a estrutura/copa das árvores estão intrinsecamente ligadas ao processo de decomposição, visto que promovem alterações na qualidade do substrato, interferem no microclima, na umidade do solo, bem como na disponibilidade de alimento e interação da comunidade decompositora (GRUGIKI et al., 2017).

Outro fator a ser considerado é a conectividade das áreas JA-14 e CA-17 com ecossistemas florestais e a presença de um dossel fechado em ambas, oposto ao observado na área IV-13 (COSTA et al., 2017). Tais características são indícios de que as 
condições edafoclimáticas explicam as diferenças encontradas quanto à porcentagem de massa remanescente, e demonstram que a conectividade de áreas restauradas a fragmentos florestais também deve ser considerada em projetos de restauração ambiental.

Por meio da análise da correlação linear de Pearson $(r)$ foi averiguado que houve correlação moderada entre a massa foliar remanescente e a precipitação para IV-13, ou seja, a decomposição foi um pouco influenciada por essa variável ambiental. Para os demais parâmetros e áreas, a correlação de Pearson foi caracterizada como fraca (Tabela 1).

Tabela 1 - Correlação de Pearson ( $r$ ) entre a massa remanescente e as variáveis ambientais (precipitação e temperatura) em três áreas de restauração, MS, Brasil

\begin{tabular}{lcc}
\hline \multicolumn{1}{c}{$\begin{array}{c}\text { Correlação de } \\
\text { Pearson }\end{array}$} & \multicolumn{2}{c}{ Massa remanescente } \\
\cline { 2 - 3 } CA-17 & Precipitação & Temperatura \\
IV-13 & 0,1417 & 0,2109 \\
JA-14 & 0,6385 & 0,2640 \\
\hline
\end{tabular}

Fonte: Autores (2019)

Em que: CA-17 (Caarapó - 17 anos); IV-13 (Ivinhema - 13 anos); JA-14 (Jateí - 14 anos).

Os resultados corroboram estudos de Bakker, Carrenõ-Rocabado e Poorter (2011), Nunes e Pinto (2012) e Bauer, Führ e Schmitt (2017) que também não observaram forte correlação entre a massa remanescente e a precipitação e a temperatura em áreas de Floresta Atlântica.

Considerando-se que a coleta do presente estudo iniciou no último mês do verão, sugere-se que em estudos futuros, tanto para as áreas em questão, quanto para locais com estações climáticas bem definidas, a análise da decomposição como indicador de áreas restauradas seja realizada em mais de uma época do ano (abrangendo os meses mais representativos do verão e inverno), ou por pelo menos um ano. Ferreira et al. (2014) também consideram importante a realização de uma investigação interanual futura para verificar se há um padrão no resultado sazonal e 
Fróes, C. Q.; Fernandes, S. S. L.; Junglos, M. S.; Costa, P. F.; Linê, J. D. B.; Pereira, Z. V. | 1335

se as variáveis ambientais são significativas à decomposição.

A constante de decomposição $(k)$ foi de $0,004 \mathrm{~g} \mathrm{~g}^{-1}$ dia-1 $^{-1}$ para CA-17, sendo essa referente à velocidade de decomposição. Já o tempo de meia-vida (t 1 1/2), que representa o tempo médio necessário para decompor 50\% do material foliar foi estimado em 194 dias (Tabela 2). Para JA-14 e IV-13, a constante de decomposição ( $k$ ) foi estimada em 0,003 $\mathrm{g} \mathrm{g}^{-1} \mathrm{dia}^{-1}$ e o tempo de meia-vida foi 218 e 269 dias, respectivamente (Tabela 2).

Tabela 2 - Constante de decomposição ( $k$ ) e tempo de meia-vida (t 1/2) ao fim de 180 dias, em três áreas de restauração ambiental do Mato Grosso do Sul, 2017

\begin{tabular}{|c|c|c|}
\hline Áreas de restauração & Constante de decomposição & Tempo de meia vida $\left(\mathrm{t}^{1 / 2}\right)$ \\
\hline do MS & $\left(\mathrm{g} \mathrm{g}^{-1} \mathrm{dia}^{-1}\right)$ & (dias) \\
\hline CA-17 & 0,004 & 194,89 \\
\hline IV-13 & 0,003 & 269,49 \\
\hline JA-14 & 0,003 & 218,29 \\
\hline
\end{tabular}

Fonte: Autores (2019)

Em que: CA-17 (Caarapó - 17 anos); IV-13 (Ivinhema - 13 anos); JA-14 (Jateí - 14 anos).

Em levantamento realizado em florestas naturais de diferentes estágios sucessionais a constante de decomposição $(k)$ variou de 0,002 a 0,005 e o tempo meiavida (t 1/2) de 151 a 315 dias (Tabela 3).

Tabela 3 - Decomposição foliar em fragmentos de Florestas Tropicais no Brasil

\begin{tabular}{lccc}
\hline \multicolumn{1}{c}{ Fisionomia } & $(\boldsymbol{k}) \mathbf{g ~ g ~}^{-1} \mathbf{~ d i a}^{-1}$ & $\mathbf{t}^{\mathbf{1 / 2}}$ ) (dias) & Referências \\
\hline Floresta Estacional Semidecidual (inicial) & 0,002 & 315 & MACHADO et al. (2015) \\
$\begin{array}{l}\text { Floresta Estacional Semidecidual } \\
\text { (intermediário) }\end{array}$ & 0,003 & 217 & MACHADO et al. (2015) \\
$\begin{array}{l}\text { Floresta Estacional Semidecidual (avançado) } \\
\text { Floresta Estacional Semidecidual (inicial) }\end{array}$ & 0,005 & 151 & MACHADO et al. (2015) \\
$\begin{array}{l}\text { Floresta Estacional Semidecidual } \\
\text { (intermediário) }\end{array}$ & 0,004 & 157 & MENEZES et al. (2010) \\
$\begin{array}{l}\text { Fragmento de Floresta Atlântica } \\
\text { Fragmento de Floresta Atlântica }\end{array}$ & 0,004 & 182 & MENEZES et al. (2010) \\
Fragmento de Floresta Atlântica & 0,003 & 248 & CUNHA-NETO et al. (2013) \\
\hline
\end{tabular}

Fonte: Autores (2019) 
Se for comparada a Floresta Estacional Semidecidual de estágio inicial (FEI) de Machado et al. (2015) que possui idade mais próxima com as áreas restauradas, observa-se que as três áreas de restauração do Mato Grosso do Sul obtiveram as constantes de decomposição similares, e (t 1/2) inferiores, o que demonstra uma decomposição mais rápida, provavelmente devido às condições de precipitação, que foram mais bem distribuídas para o MS nos períodos do outono e inverno do que em estudo de Machado et al. (2015), com menores índices de precipitação para esse período. Quando se comparam os resultados obtidos para Floresta Estacional Semidecidual de estágio intermediário (FEM) observa-se que CA-17 obteve melhores resultados, enquanto que a área de JA-14 obteve grande semelhança com a área intermediária de Machado et al. (2015).

O estudo de Menezes et al. (2010) em Floresta Estacional Semidecidual de estágio intermediário obteve constante de decomposição (k) e tempo meia-vida (t 1/2) de 0,0038 g g-1 dia-1 e 182 dias, respectivamente. A área de restauração ambiental CA-17 obteve resultados similares a estes encontrados.

Em fragmentos secundários de Floresta Atlântica, foram observados os seguintesvalores: (k) 0,0026 e (t 1/2) 266 dias (CUNHA-NETO et al., 2013), (k) 0,0027 e (t 1/2) 248 dias (FERREIRA et al., 2014), (k) 0,0027 g g-1 dia-1 e (t 1/2) 251 dias (BAUER; FÜHR; SCHMITT, 2017). Desse modo, percebe-se que o tempo meia-vida da fração foliar esteve entre 248 e 266 dias para esses estudos, e que, quando comparados, CA17 e JA-14 obtiveram tempo de decomposição foliar menores.

Com base nos levantamentos, os resultados obtidos para CA-17 e JA-14 indicam que ambas apresentam condições favoráveis ao processo de decomposição, o que é muito importante, principalmente ao se considerar que são áreas restauradas por plantio de mudas, implantadas em locais que, segundo Costa et al. (2017), anteriormente eram utilizados para fins agrícolas. Quanto a IV-14, acredita-se que a composição vegetal, a baixa diversidade de espécies arbóreas em estágio mais avançado de sucessão e a cobertura florestal, aliada ao fator de isolamento do 
fragmento de restauração, interferem na funcionalidade do ecossistema e, portanto, na decomposição foliar.

Em suma, quanto mais acelerada a decomposição, mais rápido ocorre a liberação de nutrientes para as plantas e demais processos de ciclagem que auxiliam no sustento da vegetação, o que é essencial para a sustentabilidade ecológica de áreas de restauração. Os resultados do presente estudo evidenciaram que a decomposição mais acelerada ocorreu para a área restaurada de CA-17, seguida de JA-14, e a decomposição mais lenta prevaleceu para a área de IV-13 (Tabela 3). Ressalta-se que tais resultados foram fortemente influenciados pelas características internas e externas das áreas, visto que, enquanto CA-17 e JA-14 são áreas de restauração com maior diversidade de espécies, de comportamentos diferentes (categorias sucessionais), dossel fechado e conectadas a outros remanescentes florestais, IV-14 possui condições adversas (baixa diversidade de espécies, dossel mais aberto com presença de clareiras, alta expressividade de gramíneas, entorno sem conectividade com fragmentos florestais, apenas matrizes agrícolas). Bargali et al. (2015) destacam que características bióticas e abióticas influenciam a velocidade de decomposição.

Em estudo de Pimenta et al. (2011), em Floresta Estacional Semidecidual, a menor decomposição no reflorestamento foi atribuída à maior luminosidade e à menor umidade relativa, propiciada pela maior abertura do dossel. Nunes e Pinto (2012) também correlacionaram a umidade atmosférica de forma significativa com a decomposição, resultante da estrutura e composição das espécies e do fechamento do dossel.

A área de restauração em CA-17 apresenta o dossel mais fechado, seguido da área de JA-14, o que traz a realidade inversa ao constatado por Pimenta et al. (2011). Ao longo dos anos, essas áreas criaram um microclima mais favorável, com condições de luminosidade, temperatura, umidade do solo, entre outros fatores, que são determinantes para as taxas de decomposição. Nunes e Pinto (2012) também observaram esse comportamento, detectando que o dossel fechado criou condição 
microclimática adequada à decomposição, que sob menor penetração de luz, propiciou maior estabilidade climática, maior umidade atmosférica e baixa temperatura, e em dossel mais aberto, verificou que o mesmo permite maior incidência de radiação solar, contribui para o aumento da temperatura e diminui a umidade.

Conforme levantamento florístico de Costa et al. (2017), as áreas de CA-17 e JA-14 possuem uma diversidade de espécies bem maior do que a constatada em IV13. Essa heterogeneidade de espécies também pode inferir na decomposição das áreas, pois a qualidade físico-química do material foliar é um agente condicionante desse processo (BAKKER; CARRENÕ-ROCABADO; POORTER, 2011). Segundo Muscardi, Schoereder e Sperber (2014), existe uma relação positiva entre a heterogeneidade vegetal e os organismos decompositores, que possuem necessidades alimentícias diferentes ou habilidades diversas para explorar os recursos advindos da variedade de espécies de plantas. Desse modo, subentende-se que quanto maior a diversidade da composição vegetal, maior a abundância e diversidade de organismos específicos, facilitadores da decomposição.

Biasi, Cerezer e Santos (2016) detectaram que as características físicas das folhas como a dureza influenciam muito mais as taxas de decomposição do que a característica química das mesmas. Para Schumacher e Viera (2015), um fator que induz o aumento ou diminuição da taxa de decomposição é a composição estrutural dos tecidos foliares, pois tecidos que contêm maiores teores de celulose, hemicelulose e lignina, por exemplo, são mais resistentes à decomposição do que os tecidos com menores teores desses compostos.

Embora as áreas de restauração por plantio de mudas estejam dentro dos valores encontrados para a constante de decomposição e tempo meia-vida em áreas naturais de referência com diferentes estágios sucessionais (Tabela 3), o estudo da decomposição foliar, quando visto de maneira isolada, não é suficiente para definir o estado de resiliência dessas áreas. O ecossistema florestal é dinâmico e complexo, e necessita da compreensão de outros indicadores complementares 
como fitossociologia, regeneração natural, chuva de sementes, análise química da serapilheira foliar, atividade microbiana do solo, fauna epigeica, para auxiliar no monitoramento de áreas em processo de restauração ecológica.

A decomposição da serapilheira no período avaliado permitiu a compreensão da velocidade de decomposição em diferentes áreas restauradas, comprovando a importância da dinâmica de decomposição foliar como indicador de funcionalidade do ecossistema florestal. Das três áreas estudadas, CA-17 foi a que apresentou menor tempo de meia-vida (t²/2), seguida de JA-14, resultando na decomposição mais rápida e que, segundo Pimenta et al. (2011), colabora para a eficiência da ciclagem de nutrientes no ecossistema.

\section{CONCLUSÕES}

A pouca diferença de idade das áreas de restauração não é determinante para os resultados de decomposição, a mesma é regida principalmente pelas características internas e externas das áreas.

A análise da decomposição foliar é considerada um indicador eficiente na compreensão das taxas de decomposição, demonstrando que a perda de massa foliar mais acelerada foi para CA-17, seguida de JA-14, o que pode resultar na mais rápida liberação de nutrientes para o solo e consequentemente no retorno deles para o sustento da vegetação, o que é essencial para a manutenção de ecossistemas em processo de restauração ecológica.

Recomenda-se que em localidades com estações climáticas bem definidas, estudos futuros que visem à aplicabilidade da decomposição no monitoramento de áreas restauradas sejam realizados em mais de uma época, contemplando os meses mais representativos do verão e inverno ou em um intervalo anual, a fim de detectar se as variações sazonais são significativas à decomposição. Sugere-se também a análise de indicadores complementares para compreender de maneira holística a dinâmica desses ecossistemas florestais. 


\section{AGRADECIMENTO}

À CAPES pela bolsa de doutorado concedida ao primeiro autor.

\section{REFERÊNCIAS}

ANDERSON, J. M., INGRAM, J. S. I. Tropical soil biology and fertility: a handbook of methods. 2th ed. Wallingford: CAB International, 1996. 171 p.

AGRITEMPO. Sistema de monitoramento agrometeorológico. São Paulo: Embrapa; Cepagri, 2017. Disponível em: https://www.agritempo.gov.br/agritempo/jsp/Estatisticas/index. jsp?siglaUF=MS. Acesso em: 30 set. 2017.

BAKKER, M. A.; CARRENÕ-ROCABADO, G.; POORTER, L. Leaf economics traits predict litter decomposition of tropical plants and differ among land use types. Funtional Ecology, [s. I.], v. 25, n. 1, p. 473-483, jun. 2011.

BARGALI, S. S. et al. Leaf litter decomposition and nutrient dynamics in four tree species of dry deciduous forest. Tropical Ecology, Cambridge, v. 56, n. 2, p. 191-200, may 2015.

BAUER, D.; FÜHR, C. S.; SCHMITT, J. L. Dinâmica do acúmulo e decomposição de serapilheira em Floresta Estacional Semidecidual Subtropical. Pesquisas, Botânica, São Leopoldo, n. 70, p. 225-235, abr. 2017.

BIASI, C.; CEREZER, C.; SANTOS, S. Biological colonization and leaf decomposition in a subtropical stream. Ecología Austral, Córdoba, v. 26, n. 2, p. 189-199, ago. 2016.

CALDEIRA, M. V. W. et al. Biomassa e nutrientes da serapilheira em diferentes coberturas florestais. Comunicata Scientiae, Piauí, v. 4, n. 2, p. 111-119, abr. 2013.

CALLEGARI-JACQUES, S. M. Bioestatística: princípios e aplicações. Porto Alegre: Artmed, 2003.

COSTA, P. F. et al. Composição florística e estrutura fitossociológica de três áreas de restauração florestal localizadas no estado do Mato Grosso Do Sul, MS. In: ALFARO, A. T. S.; TROJAN, D. G. (org.). Descobertas das Ciências agrárias e ambientais. 3. ed. Ponta Grossa, PR: Editora Atena, 2017. p. 107-145.

CUNHA NETO, F. V. et al. Acúmulo e decomposição da serapilheira em quatro formações florestais. Ciência Florestal, Santa Maria, v. 23, n. 3, p. 379-387, jul. 2013.

FERREIRA, M. L. et al. Litter fall production and decomposition in a fragment of secondary atlantic forest of São Paulo, SP, Southeastern Brazil. Revista Árvore, Viçosa, MG, v. 38, n. 4, p. 591-600, jul. 2014.

GIEBELMANNA, U. C. et al. Diversity and ecosystem functioning: Litter decomposition dynamics in the Atlantic Rainforest. Applied Soil Ecology, Amsterdam, v. 46, n. 2, p. 283-290, oct. 2010. 
GRUGIKI, M. A. et al. Decomposição e Atividade Microbiana da Serapilheira em Coberturas Florestais no Sul do Espírito Santo. Floresta e Ambiente, Seropédica, v. 24, p. 1-12, abr. 2017.

HÄTTENSCHWILER, S. et al. Leaf traits and decomposition in tropical rainforests: revisiting some commonly held views and towards a new hypothesis. New Phytologist, Cambridge, v. 189, n. 4, p. 950-965, oct. 2011.

HOLANDA A. C. et al. Decomposição da serapilheira foliar e respiração edáfica em um remanescente de Caatinga na Paraíba. Revista Árvore, Viçosa, MG, v. 39, n. 2, p. 245-254, 2015.

MACHADO, D. L. et al. Ciclagem de nutrientes em diferentes estágios sucessionais da Mata Atlântica na bacia do Rio Paraíba do Sul, RJ. Bioscience Journal, Uberlândia, v. 31, n. 4, p. 1222-1237, jul. 2015.

MARTINS, S. V.; RODRIGUES, R. R. Produção de serapilheira em clareiras de uma Floresta Estacional Semidecidual no município de Campinas, SP. Revista brasileira de Botânica, São Paulo, v. 22, n. 3, p. 405-412, dez. 1999.

MATO GROSSO DO SUL. Secretaria de Estado do Meio Ambiente e Desenvolvimento Econômico. Geoambientes da Faixa de Fronteira GTNF/MS. Campo Grande: Governo do Estado de Mato Grosso do Sul, 2016. 501 p.

MENEZES, C, E. G. et al. Aporte e decomposição da serapilheira e produção de biomassa radicular em florestas com diferentes estágios sucessionais em Pinheiral, RJ. Ciência Florestal, Santa Maria, v. 20, n. 3, p. 439-452, jul. 2010.

MIRANDA NETO, A. et al. Litter production and leaf litter decomposition in mined area in restoration process in southeast Brazil. Australian Journal of Basic and Applied Sciences, [s. I.], v. 9, n. 23, p. 321-327, jul. 2015.

MUSCARDI, D. C.; SCHOEREDER, J. H.; SPERBER, C. F. Biodiversity and Ecosystem Functioning: a Conceptual Model of Leaf Litter Decomposition. In: GRILLO, Oscar (ed.). Biodiversity: the dynamic balance of the planet. [S. I.]: InTech, 2014. p. 33-50.

NUNES, F. P.; PINTO, M. T. C. Decomposição do folhedo em reflorestamento ciliar na bacia hidrográfica do Rio São Francisco, Minas Gerais. Cerne, Lavras, v. 18, n. 3, p. 423-431, jul. 2012.

OLSON, J. S. Energy storage and the balance of producers and decomposers in ecological systems. Ecology,[s. I.], v. 44, n. 2, p. 322-331, apr. 1963.

PAULA, R. R.; PEREIRA, M. G.; MENEZES, L. F. T. Aporte de nutrientes e decomposição da serapilheira em três fragmentos florestais periodicamente inundados na ilha da Marambaia, RJ. Ciência Florestal, Santa Maria, v. 19, n. 2, p. 139-148, abr. 2009.

PIMENTA, J. A. et al. Produção de serapilheira e ciclagem de nutrientes de um reflorestamento e de uma Floresta Estacional Semidecidual no sul do Brasil. Acta Botanica Brasílica, Belo Horizonte, v. 25, n. 1, p. 53-57, jan. 2011. 
PINTO, H. C. A. et al. Decomposição da serapilheira foliar de floresta nativa e plantios de Pterogyne nitens e Eucalyptus urophylla no sudoeste da Bahia. Ciência Florestal, Santa Maria, v. 26, n. 4, p. 1141-1153, dez. 2016.

SCORIZA, R. N.; PIÑA-RODRIGUES, F. C. M. Aporte de serapilheira como indicador ambiental em fragmentos de Floresta estacional semidecidual em Sorocaba, SP. Agrária - Revista Brasileira de Ciências Agrárias, Recife, v. 8, n. 4, p. 634-640, 2013.

SCHUMACHER, M. V.; VIERA, M. Nutrients cycling in eucalyptus plantations. In: SCHUMACHER M. V.; VIERA, M. (ed.). Silviculture of eucalyptus in Brazil. Santa Maria: UFSM Publishing, 2015. p. 113-156.

VIERA, M. et al. Deposição de serapilheira e nutrientes em plantio de Eucalyptus urophylla E. globulus. Floresta e Ambiente, Seropédica, v. 21, n. 3, p. 327-338, 2014.

WANG, J. et al. Variations in leaf litter decomposition across contrasting forest stands and controlling factors at local scale. Journal of Plant Ecology, Oxford, v. 8, n. 3, p. 261-272, oct. 2015.

$\mathrm{XU}, \mathrm{X}$. et al. Leaf litter decomposition and nutrient dynamics in a subtropical forest after typhoon disturbance. Plant Ecology, Oxford, v. 173, n. 2, p. 161-170, aug. 2004.

\section{Contribuição de Autoria}

\section{1 - Caroline Quinhones Fróes}

Gestora Ambiental, Dra., Gerente Socioambiental

https://orcid.org/0000-0002-1924-7316•carolqf@hotmail.com

Contribuição: Conceituação, Curadoria de dados, Análise Formal, Metodologia, Recursos, Investigação, Visualização de dados, Validação, Escrita - primeira redação, Escrita - revisão e edição

\section{2 - Shaline Séfara Lopes Fernandes}

Agrônoma, Dra., Professora

https://orcid.org/0000-0001-8525-404X·shaline_sefara@hotmail.com

Contribuição: Conceituação, Análise Formal, Metodologia, Supervisão, Validação, Escrita - primeira redação, Escrita - revisão e edição 


\section{3 - Mário Soares Junglos}

Biólogo, Me., Doutorando

https://orcid.org/0000-0002-3854-1158•mario_junglos@yahoo.com.br

Contribuição: Análise Formal, Investigação, Validação

\section{4 - Poliana Ferreira da Costa}

Tecnóloga em Gestão Ambiental, Dra., Professora

https://orcid.org/0000-0003-1966-2330•poliferreiradacosta@hotmail.com

Contribuição: Conceituação, Curadoria de dados, Investigação, Metodologia, Recursos, Escrita - revisão e edição

\section{5 - Jósimo Diego Bazanella Linê}

Gestor Ambiental, Me., Pesquisador Autônomo

https://orcid.org/0000-0002-5914-5656•josimo_line@hotmail.com

Contribuição: Curadoria de dados, Investigação, Visualização de dados

\section{6 - Zefa Valdivina Pereira}

Bióloga, Dra., Professora

https://orcid.org/0000-0003-3344-3249•zefapereira@ufgd.edu.br

Contribuição: Conceituação, Obtenção de financiamento, Metodologia, Administração do projeto, Recursos, Supervisão

\section{Como citar este artigo}

Fróes, C. Q.; Fernandes, S. S. L.; Junglos, M. S.; Costa, P. F.; Linê, J. D. B.; Pereira, Z. V. Decomposição foliar visando ao monitoramento de áreas em processo de restauração ecológica no Mato Grosso do Sul. Ciência Florestal, Santa Maria, v. 31, n. 3, p. 1323-1343, 2021. DOI 10.5902/1980509839096. Disponível em: https://doi.org/10.5902/1980509839096. Acesso em: xx mês-abreviado. 2021. 